\title{
CHALLENGES
}

\section{Paediatric care in the Czech Republic}

Jan Janda

\section{Changes after the revolution in 1989}

The population of the Czech Republic has seen many changes in health care over the last five years. The general population had a poor opinion of the health service before the 'velvet revolution' of 1989, although the quality of paediatric care was generally thought to be reasonably good.

After the revolution the rise of capitalism saw the instigation of private health care, mainly in primary care, with the result that in 1993 nearly 70\% of paediatricians worked in the private sector. Insurance companies have also been functioning since 1993.

In 1990 the Faculty of Paediatrics was changed to the 2nd Medical School of Charles University and simultaneously pregraduate paediatric courses in other faculties outside Prague were closed. The Czech and Slovak split in 1993 saw the end of the close cooperation there had once been between the two paediatric societies; the linking federal committee was also dissolved. Despite political problems between the two countries relations have remained friendly and a journal produced by both societies, Cesko-Slovenská Pediatrie (with a circulation of about 4500) continues to appear once a month. Czech and Slovak symposia have also been organised.

\section{Contemporary problems}

What are the main problems to be solved in Czech (and to some degree Slovak) paediatrics? Newborn and infant mortality in the Czech republic is still relatively high, although in 1993 an improved rate of 8.9/1000 was recorded. The birth rate has been decreasing in the last few years and 1992 had the lowest number of deliveries since 1918 with 121705 live births.

The lack of family planning services and access to contraception is common to all postcommunist countries and in consequence there are a high number of unwanted pregnancies (only 19\% of women use oral contraceptives regularly; data from 1992). Paediatricians, teachers, and parents have compounded the problem by not taking enough responsibility for sex education in adolescents. This lack of sex education also raises concerns about the spread of AIDS. Although the incidence of AIDS is still relatively low, with only 30 deaths from AIDS and 200 known HIV carriers, we should educate our young people in the hope that it will never become a problem. Most adolescents still think that the chance of contracting AIDS is remote.

The lack of sex education and a liberal abortion law led at first to high abortion rates (about 109000 in 1990). An improvement has been seen recently, however, with about 69000 terminations in 1993.

More than $50 \%$ of first marriages take place because of pregnancy and not surprisingly they often end in divorce. At present every third marriage breaks down often because people are marrying too young: many women marry before they are 20 years old. There was an improvement in 1993 with a decrease in the number of marriages and an increase in the age of the couples - the first positive sign after many years. Most women give birth to their first child at 22-25 years; this compares with 25-30 years in Western countries.

There are no significant national minorities in the Czech Republic but there are about 150 000-200 000 gypsies of which more than $40 \%$ are children under 15 years. Their high infant mortality and hospital bed occupancy is out of proportion to their numbers in the population and in some paediatric departments they occupy $50 \%$ of hospital beds. Traditional gypsy families are breaking down and the number of battered and abused children is also increasing. They do not use contraception and consequently have a higher birth rate and younger mothers (less than 16-18 years) than the general population. They have never been fully integrated into society and all attempts to do so over the last 30 years have failed. A high crime rate has added to prejudice against this community.

There is not enough equipment in private paediatric practices and therefore they are not up to the standard of our Western neighbours. Paediatricians have to rely on regional health care centres or paediatric departments of district hospitals but hopefully the situation will gradually improve.

Another problem is the education of paediatric nurses. The educational level cannot be compared with that of Western countries as most of our nurses have a four year training course, starting at 14 years of age. Many subsequently leave the health care system because of poor salaries. A new training programme is urgently needed.

\section{Specialised paediatric centres}

Several paediatric centres were established in the Czech Republic before 1989. University 
Hospital Motol is one of the largest centres for paediatric care anywhere in the world with nearly all specialties represented. There is a specialised centre at this hospital for congenital heart anomalies, which has a close relationship with the Hospital for Sick Children, Great Ormond Street, and many doctors go for training in London. Cardiology care is therefore comparable with Western standards; prenatal diagnosis of congenital heart anomalies is also performed there.

Since 1980 the hospital has also had a centre specialising in paediatric dialysis and transplantation. Since then about 80 kidney transplants have been performed on children from 2.5 to 18 years of age. This centre also has close ties with other European departments, mainly in Austria and Germany, where training and scholarships are offered to our doctors. Long term results show that the quality of care offered matches that of other European countries. Another two specialised paediatric centres for dialysis and transplantation have been established in Moravia at Brno and Ostrava.

A third specialised centre at the Hospital Motol is the national centre for the diagnosis and treatment of malignant tumours in children; research is also carried out here. The standard of care is very good and doctors are very active fundraisers through the Paediatric Oncology Foundation.

Since 1991 more than 70 bone marrow transplants have been performed in the Czech Republic and more recently autologous transplants in children with solid tumours have been carried out. Paediatricians active in this field have worked and studied abroad at centres in the US and other European countries.

A paediatric transplant coordination centre was established at the Hospital Motol for kidney transplants. It has expanded its activities to include the harvesting, preservation, and transfer of cardiac valves (homografts). Because we have the ability to collect and preserve solid organs, if there is no suitable recipient in this country, organs can be offered and transferred abroad. Children needing liver transplants currently have to be treated abroad but a programme is currently being developed. We have received considerable cooperation and help from the USA and European centres. Paediatric heart transplants are still being discussed.

Two other specialised centres at the Hospital Motol worth mentioning are the centre for clinical genetics and the centre for metabolic diseases. Both these centres cooperate extensively with similar centres world wide. This cooperation is essential for the diagnosis of inborn errors of metabolism as we do not have the necessary technology at present.

A very well organised intensive paediatric diabetes programme has been introduced in the Czech Republic and is comparable with international standards. Many children with growth disturbances have profited from international studies on the effects of recombinant human growth hormone.
Other university clinics (Plzen, Hradec Kralove, Brno, and Olomouc) have recently developed their own specialised programmes in diagnostic and therapeutic care.

The only research institute for paediatrics officially partially supported by the Ministry of Health is in Brno. This institute is involved in several international projects.

\section{Patient and parent clubs}

Parental activities in clubs and associations for various diseases are very important and are flourishing after years of official neglect. Many international contacts have been made.

\section{International cooperative studies}

Participation in international cooperative studies is very important as it allows our doctors contact with leading research centres. In return we can offer relatively large patient groups, who are clinically well managed, but who do not have the opportunity for specialised laboratory investigations.

\section{Foundations}

Czech hospitals often have outdated technical equipment and special foundations and sponsoring organisations can often help in fund raising for new equipment. The Paediatric Oncology Foundation has been particularly successful and also the Olga Havel Foundation. Contributors have also come from abroad through the Medical Helpline Foundation headed by the Duchess von Schwarzenberg.

\section{Paediatric research and international contacts}

No grant system to support clinical research projects existed in the former Czechoslovakia for the previous 40 years. Because of communist ideology research was concentrated in poorly financed research institutions and cooperation with colleagues in the West was not encouraged. The need to work primarily with researchers in the former Soviet Union and other communist countries discouraged researchers learning any foreign language except Russian. As a consequence most of our paediatricians have found it very hard to get work published in leading foreign journals. A whole generation of paediatricians was cut off from what was happening in their specialty in Europe and world wide. This problem was exacerbated by the limited number of foreign medical journals that most doctors had access to. Only the willingness of our Western colleagues to send reprints, provide books and journals, and offer invitations to visit their hospitals in the West kept us in touch with what was happening in the 'outside world'. We will always be grateful to our colleagues for this and for participating in meetings here and in other socialist countries therefore giving us an opportunity to get the benefit of their experience and make personal contacts. The 
situation has changed completely now and the freedom to travel opens up many possibilities for young paediatricians where the only limitation is often the lack of knowledge of a foreign language.

Undergraduate medical student exchange We are very pleased to have the opportunity to send our medical students on electives to German and English speaking countries and to accept foreign students in Prague and at other universities in the country. University Hospital Motol had traditionally had good contacts with many other European hospitals and foreign students visiting us can return home knowing that medicine here is not still in the 'dark ages'.

\section{Medical information}

There is no longer an 'information block' and several European and American paediatric journals are now available. All university departments have access to Medline and Current contents and a new electronic mail system (EARN, European Academic Research Network) is developing rapidly and being used enthusiastically by young doctors. The number of clinics with personal computers has increased tremendously over the past three years.

\section{Introduction of family doctors}

Paediatricians take full care of children but recently the idea of introducing the system of family doctors has been discussed and the way things are done in different countries looked at. Most paediatricians believe that it is very difficult for a family doctor to ensure full quality care from the prenatal period until old age. Because of long experience with the integration of preventive and therapeutic care in this country paediatricians prefer to maintain the status quo and not change the system just because it was created during the totalitarian regime.

In general, paediatricians in Europe and the USA earn less than other specialties; paediatricians therefore see their work more as a vocation. Prevention is an important part of modern child care and because children and their parents do not have much power paediatricians should help act as a lobbyists for their welfare in our society. We are not convinced that family doctors would be willing and capable of fulfilling this role.

\section{Paediatric scientific and professional organisations}

The Czech Pediatric Society is fully integrated in the Czech Medical Society of Jan Evangelista Purkyne. It has about 1800 members and close links with the Czech Neonatology Society, the Czech Society for Social Pediatrics, and the Society for Adolescent Medicine. The main activity of the society is to organise scientific meetings and coordinate special working groups in all areas of paediatrics. The success of the British Paediatric Association's British Paediatric Surveillance Unit had lead us to introduce a similar system for surveillance of childhood diseases. Many of our members are also members of specialist European societies.

A professional organisation was founded two years ago to protect the economic and professional interest of primary care paediatricians working mainly in private practice. This organisation has close ties with insurance companies and with the Ministry of Health.

We plan to create an 'umbrella' organisation for all aspects of child care.

\section{Future of Czech paediatrics}

The future of Czech paediatrics lies in the hands of young paediatricians, particularly those who have studied abroad and worked with the latest technology; the knowledge of foreign languages is a prerequisite. Their role is to maintain our high standards of primary care and encourage the expansions of ambulatory paediatrics and hospital care for children and adolescents. Scientific research must also not be neglected.

The standard of Czech paediatrics is fast catching up with that of its Western European neighbours. It may take a while but we believe and hope that full integration will be quicker than the 44 years from $1945-89$ ! 